\title{
Rizatriptan in the treatment of migraine
}

\section{Miguel JA Láinez}

Department of Neurology, University Clinic Hospital, University of Valencia, Valencia, Spain
Correspondence: Miguel JA Láinez Department of Neurology, University Clinic Hospital, University of Valencia, Avda Blasco Ibáñez 17, 460I0 Valencia, Spain

Tel +34963868863

Fax +34963900 321

Email jlaineza@meditex.es
Abstract: Migraine is a common, disabling disorder associated with considerable personal and societal burden. Current guidelines recommend triptans for the acute treatment of migraine unlikely to respond to less effective therapies. Rizatriptan is a second-generation triptan available in tablet or orally disintegrating tablet (wafer) formulations that offers several advantages over other members of its class. Rizatriptan is rapidly absorbed from the gastrointestinal tract and achieves maximum plasma concentrations more quickly than other triptans, providing rapid pain relief. Clinical trials have shown that rizatriptan is at least as effective or superior to other oral migraine-specific agents in the acute treatment of migraine, and has more consistent long-term efficacy across multiple migraine attacks. Rizatriptan has a favorable tolerability profile, and patients have reported greater satisfaction and a preference for rizatriptan over other migraine-specific agents. Improvements in quality of life reported with rizatriptan are consistent with its favorable efficacy and tolerability profiles. Notably, multi-attribute decision models that combine clinical data with patient- and physician-reported treatment preferences have identified rizatriptan as one of three triptans closest to a hypothetical "ideal". The efficacy and tolerability of rizatriptan for the acute treatment of migraine have thus been well established.

Keywords: rizatriptan, serotonin receptor agonists, triptans, acute migraine

\section{Introduction}

\section{Background and epidemiology}

Migraine is a common, disabling disorder that affects approximately $3 \%-22 \%$ of females and $1 \%-16 \%$ of males worldwide (Lipton and Bigal 2005). Results of a large population-based study performed in the US suggest that migraine affects approximately $18.2 \%$ of women and $6.5 \%$ of men, of whom most (62\%) experience at least 1 severe headache per month (Lipton, Stewart, et al 2001). Migraine without aura is the commonest clinical subtype of migraine, and has a higher attack frequency and is generally more disabling than migraine with aura (HCS 2004). Migraine without aura is defined as a recurrent disorder that involves headache attacks lasting 4 hours to 3 days, with at least 2 of the following characteristics: unilateral pain, pulsating quality, aggravation on movement, and pain of moderate or severe intensity (HCS 2004). Patients with this migraine subtype also experience nausea and/or vomiting, and/or photophobia and phonophobia (HCS 2004).

Migraine places a considerable burden on the sufferer, their friends and family, and society, in terms of economic costs and quality of life. Direct costs of migraine include visits to physicians, utilization of emergency care facilities, and prescription and over-the-counter medications (Lipton and Bigal 2005). The majority of the not inconsiderable indirect costs are borne by patients and their employers, predominantly as a result of bedridden days and impaired work function (Hu et al 1999). A recent analysis, based principally on studies performed prior to 1995 , estimated that the annual cost of migraine in some Western European countries was approximately 
€590 per patient, primarily due to lost productivity (Berg and Stovner 2005). Lost productivity due to headache (including but not limited to migraine) is estimated to cost more than US\$19 billion per year in the US, with migraine accounting for at least US\$13 billion per year (Hu et al 1999).

The results of several studies indicate that migraine affects quality of life during and immediately after a migraine attack, as well as reducing quality of life between episodes (Lipton and Bigal 2005). Population-based studies in the UK and US demonstrate that migraine attacks also have a significant impact on family members of afflicted individuals (Lipton et al 2003). Moreover, a survey of migraine sufferers found that less than one-third of patients were "very satisfied" with their acute migraine treatment (Lipton and Stewart 1999). Thus, migraine remains a major healthcare problem, and there is significant opportunity to improve the treatment and management of this condition.

\section{Current treatments}

There are a number of abortive therapy options for acute migraine. Nonsteroidal anti-inflammatory agents, nonopiate analgesics, and combination analgesics may be appropriate for some patients with mild-to-moderate migraine. Patients with moderate-to-severe symptoms or those who respond poorly to adequate doses of analgesics generally require migraine-specific agents or more potent nonspecific agents such as opiate analgesics, although the latter should be used sparingly (Silberstein and for the US Headache Consortium 2000; Goadsby et al 2002). Anti-emetics may be used to treat migraine-associated nausea, and may also facilitate absorption of oral migraine treatments by improving gastric motility.

The two principal classes of migraine-specific agents (ie, those targeting the neurovasculature) are the ergot derivatives and the triptans. The ergot derivatives ergotamine and dihydroergotamine have been used for the acute treatment of migraine for many years. However, they have a number of limitations including nonspecific vasoconstrictor effects and other side-effects (eg, nausea and vomiting) owing to a low degree of receptor selectivity, and there is a lack of consistent efficacy data for these agents (Tfelt-Hansen, Saxena, et al 2000). Improved understanding of the pathology of migraine led to the development of selective serotonin (5-hydroxytryptamine $[5-\mathrm{HT}]$ ) receptor agonists (triptans) that activate $5-\mathrm{HT}_{1 \mathrm{~B}}$ and $5-\mathrm{HT}_{1 \mathrm{D}}$ receptors. Triptans are now generally preferred over ergot derivatives in treating most patients with migraine, because of advantages including selective pharmacology and well-established efficacy and safety (Goadsby et al 2002).

Sumatriptan was the first triptan to be introduced for the treatment of migraine attacks, and is commonly used as the reference against which later triptans are compared (Ferrari et al 2002). Although clinical trial results show only relatively small differences between sumatriptan and newer, second-generation triptans for efficacy and tolerability, these differences are considered clinically relevant for individual patients (Ferrari et al 2002). This article reviews the evidence relating to rizatriptan, a second-generation triptan available in 5- and 10-mg tablets and orally disintegrating tablets (wafers) for the acute treatment of migraine.

\section{Pharmacology}

\section{Animal and preclinical results}

Several pharmacologic effects of the $5-\mathrm{HT}_{1 \mathrm{~B} / 1 \mathrm{D}}$ receptor agonist rizatriptan are thought to contribute to its antimigraine activity, including vasoconstriction of intracranial extracerebral blood vessels (Longmore et al 1998), inhibition of nociceptive neurotransmission in trigeminal pain pathways (Cumberbatch et al 1997), and inhibition of neurogenic dural vasodilation and plasma protein extravasation (Williamson et al 1997; Williamson et al 2001).

Preclinical studies showed that rizatriptan caused vasoconstriction in isolated human cranial (middle meningeal) arteries (Longmore et al 1998) with an $\mathrm{EC}_{50}$ (concentration required to produce $50 \%$ of maximum vasoconstriction) of $90 \mathrm{nM}$, which is similar to the maximum plasma concentrations achieved following oral administration of a single 5- or 10-mg rizatriptan dose in healthy individuals (30-70 nM) (Sciberras et al 1997). The vasoconstrictor action of rizatriptan is thought to occur primarily via $5-\mathrm{HT}_{1 \mathrm{~B}}$ receptors (Longmore et al 1998; Goadsby and Hargreaves 2000). A study in healthy volunteers showed that rizatriptan significantly reduced cerebral blood flow and arterial-to-capillary blood volume consistent with its vasoconstrictor activity in large cerebral arteries, with a recovery pattern indicating no alteration of the autoregulatory response of small arteries (Okazawa et al 2005). Another study in healthy volunteers found no effect of rizatriptan $40 \mathrm{mg}$ on regional cerebral blood flow (Sperling and Tfelt-Hansen 1995). Furthermore, rizatriptan did not significantly alter cerebral blood flow velocity during attacks in patients with migraine without aura as compared 
with pretreatment or pain-free values, a finding that may support the cerebrovascular safety of the drug (Gori et al 2005). Although, like other triptans, rizatriptan has also been shown to contract isolated human coronary arteries in vitro (Longmore et al 1997; MaassenVanDenBrink et al 1998), the $\mathrm{EC}_{50}$ for this effect (700-1000 nM) (Longmore et al 1997) is so high that rizatriptan is considered unlikely to cause myocardial ischemia at therapeutic plasma concentrations in patients with normal coronary circulation (MaassenVanDenBrink et al 1998). Rizatriptan $10 \mathrm{mg}$ demonstrated only minimal and transient vasoconstrictor effects on peripheral arteries in normal human subjects (Tfelt-Hansen et al 2002).

\section{Pharmacokinetics}

Rizatriptan is rapidly and completely $(\sim 90 \%)$ absorbed from the gastrointestinal tract following administration of the oral tablet, with an absolute bioavailability of $47 \%$ owing to moderate first-pass metabolism (Vyas et al 2000). The mean time to maximum plasma concentration $\left(\mathrm{t}_{\max }\right)$ following a single rizatriptan 10-mg tablet in healthy volunteers is approximately $1-1.5$ hours (Sciberras et al 1997; Goldberg et al 2000; Vyas et al 2000), which is shorter than that of other available triptans (Ferrari et al 2002). Rizatriptan has a relatively short plasma half-life $\left(\mathrm{t}_{1 / 2}\right)$ of approximately $2-2.5$ hours (Sciberras et al 1997; Lee et al 1999; Goldberg et al 2000; Vyas et al 2000). A pharmacokinetic study in healthy males showed no unexpected accumulation of rizatriptan $10 \mathrm{mg}$ following administration of multiple doses (every 2 hours for 3 doses on 4 consecutive days) (Goldberg et al 2000). Rizatriptan wafers have a similar pharmacokinetic profile to tablets, although they have a slower rate of absorption (mean $\mathrm{t}_{\max }$ 1.6-2.5 hours) (Merck \& Co Inc. 2003).

Metabolism is the primary route of elimination of rizatriptan, with renal elimination accounting for only $25 \%$ of total plasma clearance (Vyas et al 2000). Rizatriptan is metabolized predominantly by monoamine oxidase A, accounting for $51 \%$ of urinary rizatriptan metabolites (Vyas et al 2000). The clearance of rizatriptan is approximately $25 \%$ higher in males than in females (plasma clearance 1042 vs $821 \mathrm{~mL} / \mathrm{min}$, respectively); however, this is not thought to be clinically relevant (Lee et al 1999).

Importantly, rizatriptan mean plasma concentrations and $\mathrm{t}_{\max }$ are not affected by the occurrence of a migraine attack (and associated gastric stasis) (Cutler et al 1999). Administration of food prior to rizatriptan dosing in healthy volunteers was found to increase the area under the curve (AUC) by approximately $20 \%$ and delay absorption, but there were no significant effects on maximum concentration $\left(\mathrm{C}_{\max }\right)$ or $t_{\max }$ values (Cheng et al 1996). The pharmacokinetics of rizatriptan in elderly patients (aged $\geq 65$ years) are similar to those in younger patients (Musson et al 2001). Since the major route of elimination of rizatriptan, oxidative deamination, is catalyzed by monoamine oxidase A, inhibitors of cytochrome P-450 are expected to have minimal effects on the pharmacokinetics of rizatriptan (Vyas et al 2000). Patients receiving propranolol exhibit an increase in plasma rizatriptan concentration (Goldberg et al 2001), possibly reflecting competitive inhibition of monoamine oxidase A rizatriptan metabolism. Rizatriptan dosereduction is therefore recommended in patients receiving propranolol (see patient support-disease management programs section).

\section{Clinical studies Efficacy}

Recommended efficacy measures in clinical trials of migraine treatments include the percentage of patients who are painfree at 2 hours following treatment, headache response-pain relief at 2 hours (reduction in intensity of the headache from severe or moderate at baseline to mild or none), sustained pain-free response rate (pain-free status within 2 hours with no rescue medication use or migraine recurrence within 48 hours), time to headache response or pain-free status (ie, speed of onset of action), and the need for rescue medications within 2 hours of treatment (Tfelt-Hansen, Block, et al 2000).

The efficacy of rizatriptan 5 and $10 \mathrm{mg}$ in acute migraine has been clearly established in randomized, double-blind, placebo-controlled trials (Visser et al 1996; Gijsman et al 1997; Goldstein et al 1998; Teall et al 1998; Tfelt-Hansen et al 1998; Ahrens et al 1999; Bomhof et al 1999; Pascual et al 2000; Kolodny et al 2004). A meta-analysis of 7 phase III, randomized, double-blind, placebo-controlled trials in which a total of 4814 patients received treatment for at least 1 migraine attack demonstrated that rizatriptan $10 \mathrm{mg}$ was significantly more effective than placebo at 2 hours on measures of pain relief, pain-free status, nausea, photophobia, phonophobia, and functional disability ( $\mathrm{p}<0.001$ for all comparisons) (Ferrari et al 2001). Furthermore, compared with placebo recipients, significantly more patients taking rizatriptan $10 \mathrm{mg}$ had sustained pain relief (18\% vs 37\%, respectively, $\mathrm{p}<0.001)$ and pain-free status ( $7 \%$ vs $25 \%$, $\mathrm{p}<0.001$ ) over 24 hours. The results of these trials have 

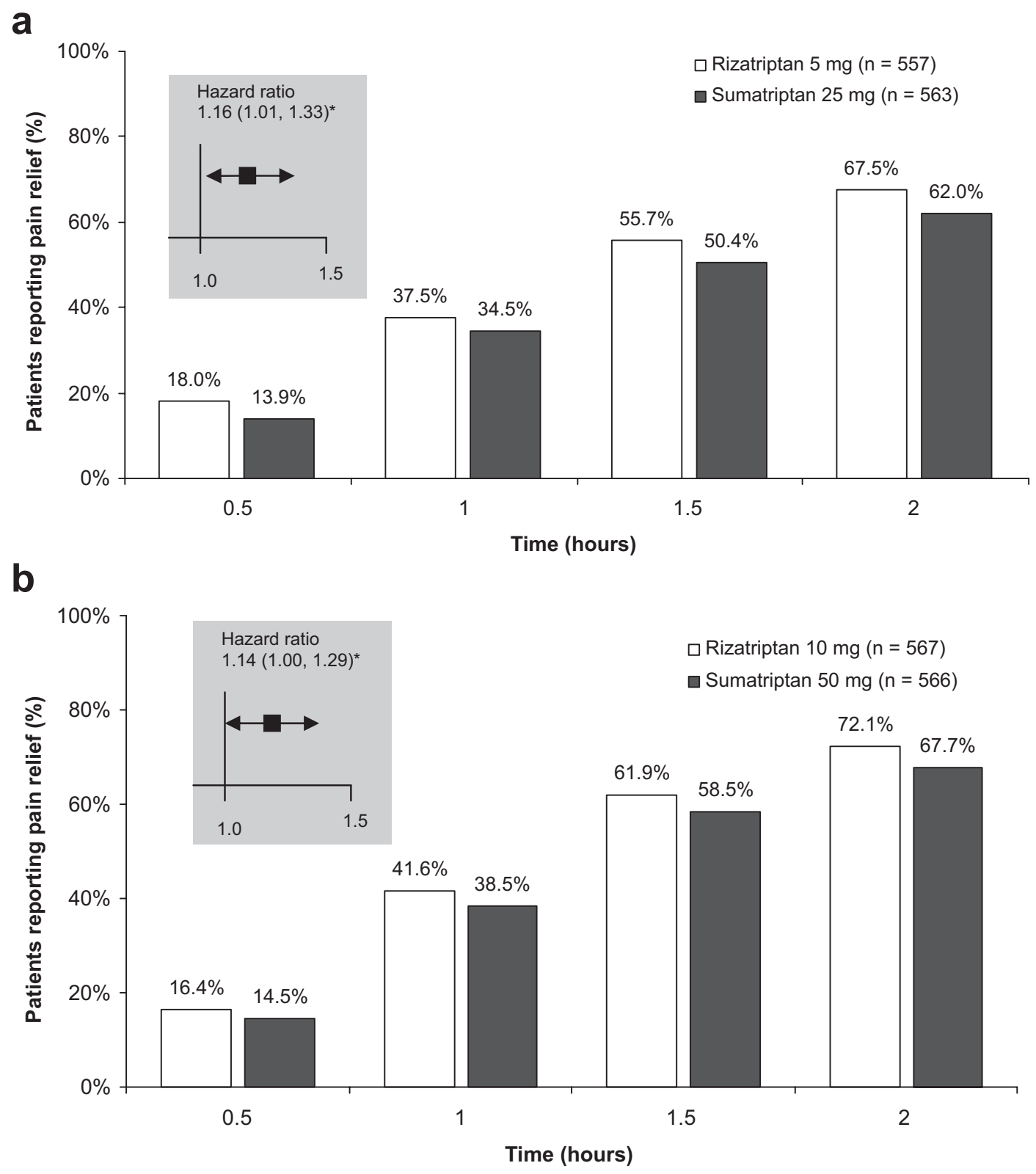

Figure I Patients reporting pain relief at time points up to 2 hours following dosing with rizatriptan or sumatriptan in a randomized, double-blind, placebo-controlled, cross-over study (Goldstein et al 1998). Adults with at least a 6-month history of migraine with or without aura were randomized to treat 2 sequential migraine attacks of moderate to severe intensity separated by at least 5 days. Treatment sequences included (a) rizatriptan 5 mg followed by sumatriptan 25 mg or vice versa, (b) rizatriptan $10 \mathrm{mg}$ followed by sumatriptan $50 \mathrm{mg}$ or vice versa, or placebo followed by placebo (data not shown). Hazard ratios for time to pain relief indicate that patients receiving rizatriptan were significantly more likely to achieve pain relief during the 2 -hour period than patients receiving sumatriptan. * $<0.05$. Reproduced from Goldstein J, Ryan $\mathrm{R}$, Jiang K, et al. 1998. Crossover comparison of rizatriptan $5 \mathrm{mg}$ and $10 \mathrm{mg}$ vs sumatriptan $25 \mathrm{mg}$ and $50 \mathrm{mg}$ in migraine. Rizatriptan Protocol 046 Study Group. Headache, 38:737-47. Copyright ( 1998, with permission from Blackwell Publishing Ltd.

been further confirmed in a large open-label, uncontrolled study (Göbel et al 2001).

In randomized comparative studies, rizatriptan $10 \mathrm{mg}$ was at least as effective as, or superior to, oral sumatriptan 50 or $100 \mathrm{mg}$ (Visser et al 1996; Goldstein et al 1998; TfeltHansen et al 1998; Kolodny et al 2004), zolmitriptan $2.5 \mathrm{mg}$ (Pascual et al 2000), naratriptan $2.5 \mathrm{mg}$ (Bomhof et al 1999), and ergotamine-caffeine $2 \mathrm{mg} / 200 \mathrm{mg}$ (Christie et al 2003) for a number of efficacy parameters, including headache relief and pain-free status at 2 hours, functional improvement at 2 hours, and time to headache-pain relief (Table 1, Figure 1). The proportion of patients experiencing headache recurrence was generally similar between patients taking rizatriptan and those taking comparator treatments. However, statistical analyses of this endpoint are usually not performed because recurrence is conditional on initial 


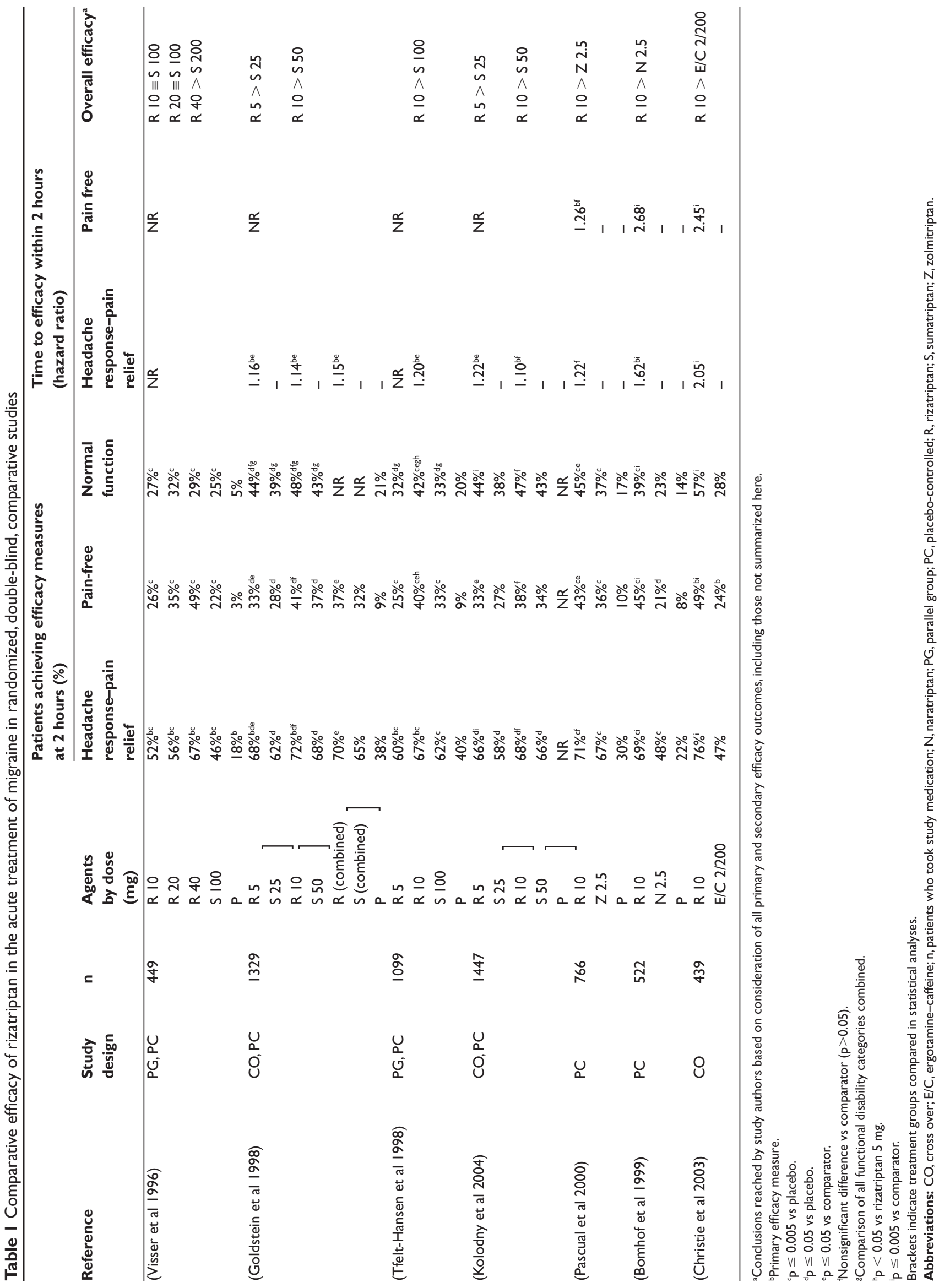


headache relief and confounded by the use of additional headache-pain medication, thus making interpretation of recurrence rates difficult.

Analyses of data from several of the above-mentioned comparator studies (Tfelt-Hansen et al 1998; Goldstein et al 1998; Bomhof et al 1999; Pascual et al 2000; Kolodny et al 2004) have confirmed the significantly greater efficacy of rizatriptan $10 \mathrm{mg}$ compared with oral sumatriptan 25,50 , or $100 \mathrm{mg}$, naratriptan $2.5 \mathrm{mg}$, and zolmitriptan $2.5 \mathrm{mg}$ for stringent efficacy measures (pain-free response at 2 hours, symptom-free response at 2 hours, and 24-hour sustained pain-free response) (Adelman et al 2001), ability to functional normally at 2 hours (Bussone et al 2002), and freedom from nausea at 2 hours (sumatriptan and naratriptan) (Lipton, Pascual, et al 2001) (Table 2).

Open-label trials have also shown benefits with rizatriptan $10 \mathrm{mg}$ wafer vs oral sumatriptan $50 \mathrm{mg}$ (Pascual et al 2001; Loder et al 2001), almotriptan $12.5 \mathrm{mg}$ (Leira et al 2003), and zolmitriptan $5 \mathrm{mg}$ (Mathew et al 2000), on efficacy measures such as greater headache relief and/or freedom from pain at 2 hours (vs sumatriptan and zolmitriptan), faster time to headache relief and pain-free status (vs sumatriptan) and reductions in number of triptan doses needed for migraine (vs almotriptan). A small single-blind, single-center, multiple-attack study comparing rizatriptan $10 \mathrm{mg}$, sumatriptan $100 \mathrm{mg}$, almotriptan $12.5 \mathrm{mg}$, zolmitriptan $2.5 \mathrm{mg}$, and eletriptan $40 \mathrm{mg}$, reported relatively homogeneous results overall, but superior efficacy with rizatriptan with respect to pain-free response at 2 hours (vs sumatriptan and almotriptan) and sustained pain-free response (vs sumatriptan) (Vollono et al 2005). The authors considered rizatriptan to have the best performance of the triptans evaluated but concluded that, owing to the unpredictability of responsiveness to individual triptans, selection of an "ideal triptan" may require a process of trial and error in each patient (Vollono et al 2005).

Patients treated with rizatriptan 10-mg tablet or wafer in a typical patient care setting reported better treatment outcomes compared with their prior migraine treatment experiences (primarily triptans, opiates and barbiturates, or nonsteroidal anti-inflammatory drugs), in terms of speed of pain relief $(18 \%$ and $23 \%$ of patients taking rizatriptan tablet or wafer, respectively, reported onset of pain relief within 30 minutes vs $16 \%$ for comparator), and 2-hour efficacy endpoints including headache response $(66 \%$ and $67 \%$ vs $37 \%$ ), pain-free status (31\% for both rizatriptan formulations vs $12 \%$ ), freedom from migraine-associated symptoms ( $52 \%$ and $54 \%$ vs $35 \%$ largely symptom-free), and ability to resume normal activities (50\% and 51\% vs 31\%) (Jamieson et al 2003). Similarly, an open-label, 2-attack study showed that among patients with functional disability at the start of a migraine attack, more patients reported a return to normal function 2 hours after treatment with rizatriptan 10-mg wafer than after treatment of the preceding attack with their usual nontriptan therapy (nonsteroidal anti-inflammatory drugs, analgesics, or ergot derivatives, used alone or in combination) (48\% vs 19\%, respectively; p < 0.001 ) (Pascual et al 2005). After adjusting for confounding factors, rizatriptan was twice as likely to return patients to normal function compared with their usual nontriptan therapy (hazard ratio 2.08; 95\% confidence interval, 1.92-2.25; $\mathrm{p}<0.001$ ), and the speed of return to normal function was significantly greater with rizatriptan therapy $(\mathrm{p}<0.001)$ (Pascual et al 2005).

Long-term studies (up to 6 months or 1 year) of acute treatment with rizatriptan tablets (Block et al 1998) or wafers (Cady et al 2001) for multiple attacks showed that rizatriptan $10 \mathrm{mg}$ was superior to rizatriptan $5 \mathrm{mg}$ or "standard care" in terms of pain relief and pain-free status at 2 hours after dosing (Figure 2). Headache relief rates were consistently maintained over the duration of the studies, with no apparent change in response over time. Importantly, there was no evidence of tolerance to the therapeutic effects of rizatriptan after up to 1 year of treatment (Block et al 1998). Rizatriptan also demonstrated consistent within-patient efficacy over multiple migraine attacks (Kramer et al 1998; Dahlof et al 2000).

Quality of life benefits, as measured by the 24-hour Migraine Quality of Life Questionnaire (Santanello et al 1995), have also been reported with rizatriptan treatment. In randomized controlled trials, rizatriptan $10 \mathrm{mg}$ was associated with significantly better migraine-specific quality of life than placebo $(p=0.005)$ (Santanello et al 1997), and provided improvements in 24-hour quality of life relative to baseline similar to those achieved with oral sumatriptan 25, 50, or $100 \mathrm{mg}$ (Goldstein et al 1998), zolmitriptan $2.5 \mathrm{mg}$ (Pascual et al 2000), and naratriptan $2.5 \mathrm{mg}$ (Bomhof et al 1999). One study found that rizatriptan $10 \mathrm{mg}$ was superior to rizatriptan $5 \mathrm{mg}$ in this regard ( $\mathrm{p} \leq 0.001$ ) (Santanello et al 1997).

Rizatriptan has demonstrated efficacy in special patient groups. In a retrospective analyses of data from a subgroup of women with menstrual migraine from 2 randomized placebo-controlled trials, rizatriptan (5 or $10 \mathrm{mg}$ ) was significantly more effective than placebo in achieving pain relief and pain-free status at 2 hours $(p<0.05$ for both 
Table 2 Efficacy of rizatriptan in the acute treatment of migraine in retrospective analyses of comparative studies

\begin{tabular}{|c|c|c|c|c|c|}
\hline \multirow[b]{2}{*}{$\begin{array}{l}\text { Agents by dose } \\
(\mathrm{mg}) \text { and } \\
\text { compator }\end{array}$} & \multicolumn{5}{|c|}{ Proportion of patients achieving efficacy measures, \% (odds ratio) } \\
\hline & $\begin{array}{l}\text { Pain-free at } 2 \text { hours } \\
\text { (Adelman } \\
\text { et al 200I) }\end{array}$ & $\begin{array}{l}\text { Symptom-free at } \\
2 \text { hours (Adelman } \\
\text { et al 200I) }\end{array}$ & $\begin{array}{l}\text { 24-hour sustained } \\
\text { pain-free response } \\
\text { (Adelman } \\
\text { et al 200I) }\end{array}$ & $\begin{array}{l}\text { Normal function } \\
\text { at } 2 \text { hours } \\
\text { (Bussone } \\
\text { et al 2002) }\end{array}$ & $\begin{array}{l}\text { Nausea-free at } \\
2 \text { hours } \\
\text { (Lipton } \\
\text { et al 200I) }\end{array}$ \\
\hline R 10 S 25 & $38 \%(1.7)^{a} 27 \%$ & $33 \%(1.6)^{a} 24 \%$ & $27 \%(1.5)^{\mathrm{a}} 20 \%$ & $48 \%(1.7)^{\mathrm{a}} 36 \%$ & $68 \%(1.4)^{\mathrm{b}} 59 \%$ \\
\hline R IOS 50 & $40 \%(1.2)^{\mathrm{b}} 35 \%$ & $33 \%(1.2)^{a} 28 \%$ & $30 \%(1.2)^{b} 26 \%$ & $47 \%(1.2)^{\mathrm{b}} 42 \%$ & $68 \%(1.5)^{\mathrm{b}} 57 \%$ \\
\hline R I0 S 100 & $40 \%(1.4)^{b} 33 \%$ & $31 \%(1.7)^{\mathrm{a}} 22 \%$ & $27 \%(1.3)^{\wedge} 23 \%$ & $39 \%(1.4)^{\mathrm{b}} 32 \%$ & $66 \%(1.4)^{b} 58 \%$ \\
\hline R $10 \mathrm{~N} 2.5$ & $45 \%(3.3)^{\mathrm{a}} 21 \%$ & $30 \%(3.6)^{\mathrm{a}} \mid 1 \%$ & $29 \%(2.0)^{\mathrm{a}} \mid 7 \%$ & $39 \%(2.5)^{\mathrm{a}} 22 \%$ & $59 \%(1.8)^{b} 45 \%$ \\
\hline R 10 Z 2.5 & $43 \%(1.4)^{\mathrm{b}} 36 \%$ & $31 \%(1.4)^{b} 24 \%$ & $32 \%(1.6)^{b} 24 \%$ & $45 \%(1.6)^{\mathrm{b}} 36 \%$ & $65 \%(1.3)^{c} 61 \%$ \\
\hline
\end{tabular}

${ }^{a} \mathrm{p} \leq 0.005$ vs comparator.

${ }^{\mathrm{b}} \mathrm{p} \leq 0.05$ vs comparator.

'Nonsignificant difference vs comparator ( $p>0.05)$.

Abbreviations: $\mathrm{N}$, naratriptan; $\mathrm{R}$, rizatriptan; $\mathrm{S}$, sumatriptan; $\mathrm{Z}$, zolmitriptan.

endpoints) (Silberstein et al 2000). Results from this and another retrospective analysis of data from a long-term (up to 6 months) extension study suggest that rizatriptan has similar efficacy in patients with menstrual migraine to that observed in patients with nonmenstrual migraine (Silberstein et al 2002). Rizatriptan $5 \mathrm{mg}$ tablets or wafers were more effective in achieving 2-hour pain relief and pain-free status than standard care (primarily ibuprofen, sumatriptan, zolmitriptan, and aspirin-acetaminophen-caffeine) in adolescents aged 12-17 years, based on pooled data from 2 long-term, openlabel studies (Visser et al 2004). In 2 randomized, doubleblind, single-attack studies in adolescent patients, rizatriptan $5 \mathrm{mg}$ tablets were not significantly different from placebo for pain relief or freedom from pain at 2 hours (Winner et al 2002; Visser et al 2004); however, there were high placebo response rates in both trials (eg, 2-hour pain relief rates with rizatriptan vs placebo were $66 \%$ vs $56 \%$ (Winner et al 2002) and $68 \%$ vs $69 \%$ (Visser et al 2004), respectively).

In most clinical trials rizatriptan was generally administered to patients with moderate-to-severe headaches; however, rizatriptan has also shown efficacy when given for mild pain in the early stages of a migraine attack (Mathew et al 2004).

A meta-analysis of results from 53 studies of oral triptans in the treatment of migraine showed that rizatriptan $10 \mathrm{mg}$ appeared to have greater intra-patient consistency for 2-hour headache response and pain-free status over 3 migraine attacks than other triptan dosages evaluated (sumatriptan 25-100 mg, naratriptan $2.5 \mathrm{mg}$, eletriptan $20-80 \mathrm{mg}$, and almotriptan $12.5 \mathrm{mg}$ ) (Ferrari et al 2002). The analysis indicated that rizatriptan $10 \mathrm{mg}$ (along with eletriptan $80 \mathrm{mg}$ and almotriptan $12.5 \mathrm{mg}$ ) was one of three triptans most likely to be associated with consistent treatment success, particularly when rapid and consistent relief of pain was required (Ferrari et al 2002).

\section{Tolerability and patient acceptability}

Rizatriptan was generally well tolerated in the aforementioned randomized, placebo-controlled studies. The frequency of adverse events with rizatriptan appears to be dose-related (Visser et al 1996; Ferrari et al 2001). In a summary of adverse event data from 7 randomized, placebo-controlled studies of rizatriptan for the acute treatment of migraine attack, specific adverse events with an incidence of $5 \%$ or more in patients receiving placebo $(\mathrm{n}=1260)$, rizatriptan $5 \mathrm{mg}(\mathrm{n}=1486)$, or rizatriptan $10 \mathrm{mg}(\mathrm{n}=2068)$ were dizziness $(4 \%, 6 \%$, and $9 \%$, respectively), somnolence $(4 \%, 5 \%$, and $8 \%$ ), nausea ( $4 \%, 5 \%$, and $6 \%$ ), and asthenia-fatigue $(2 \%$, $3 \%$, and 5\%) (Ferrari et al 2001). Similarly, the most common adverse events in patients taking rizatriptan $5-$ or $10-\mathrm{mg}$ tablet or wafer in comparative clinical trials included dizziness $(5 \%-11 \%$ of patients across clinical trials), somnolence ( $4 \%-10 \%)$, asthenia-fatigue ( $2 \%-8 \%)$, dry mouth $(2 \%-7 \%)$, nausea $(2 \%-6 \%)$, and chest pain $(1 \%-4 \%)$; these events were predominantly transient and mild or moderate in intensity (Visser et al 1996; Goldstein et al 1998; Tfelt-Hansen et al 1998; Bomhof et al 1999; Pascual et al 2000; Christie et al 2003; Kolodny et al 2004). In comparator studies, the overall incidence of drug-related adverse events in patients receiving rizatriptan $5-$ or $10-\mathrm{mg}$ tablet or wafer ranged from $23 \%$ to $37 \%$, compared with sumatriptan 25,50 , or $100 \mathrm{mg}(28 \%-41 \%)$, zolmitriptan $2.5 \mathrm{mg}$ (28\%), naratrip$\tan 2.5 \mathrm{mg}$ (19\%), and ergotamine $2 \mathrm{mg}$-caffeine $200 \mathrm{mg}$ (23\%) (Bianchi et al 1989; Goldstein et al 1998; TfeltHansen et al 1998; Bomhof et al 1999; Christie et al 2003; 


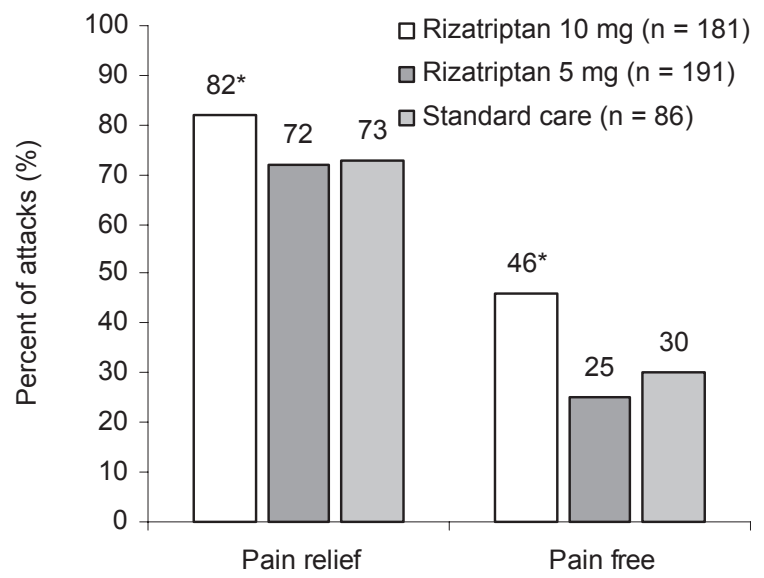

b

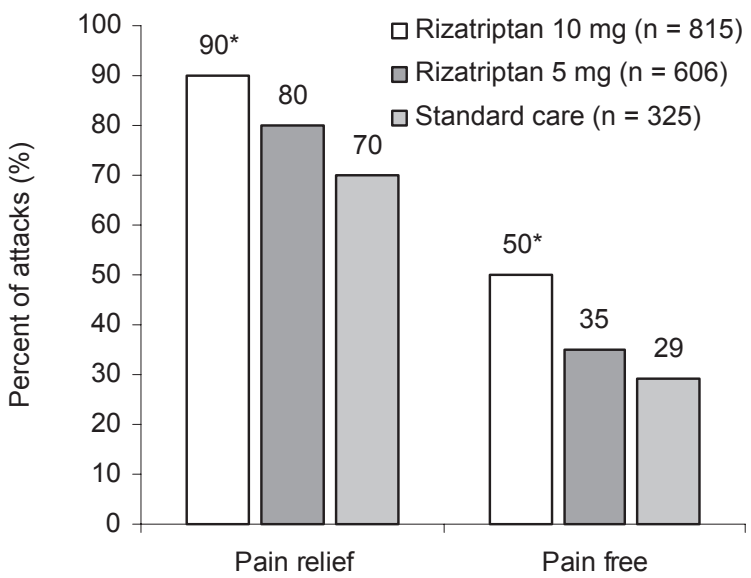

Figure 2 Median percent of migraine attacks in which patients achieved pain relief or pain-free status 2 hours after dosing. (a) Results in patients enrolled in an open-label, randomized, 6-month extension study who treated at least I moderate or severe migraine attack with rizatriptan 5-mg wafers (median of 16 attacks treated), rizatriptan 10-mg wafers (median 13 attacks treated), or standard care (primarily sumatriptan) (median 14 attacks treated). (b) Results in patients enrolled in a I2-month, randomized extension study who treated at least I migraine with rizatriptan 5-mg tablets (median of I4 attacks treated), rizatriptan I0-mg tablets (median $2 \mathrm{I}$ attacks treated), or standard care (primarily nonsteroidal anti-inflammatory drugs) (median 19 attacks treated). ${ }^{*} \mathrm{p}<0.05$ vs rizatriptan $5 \mathrm{mg}$ and vs standard care. Figure $2 \mathrm{a}$ reproduced from Cady R, Crawford G, Ahrens S, et al. 200I. Long-term efficacy and tolerability of rizatriptan wafers in migraine. Medscape General Medicine, 3(4): http://www.medscape. com/viewarticle/408I37 @ 200I Medscape; Figure 2b reproduced from Block GA, Goldstein J, Polis A, et al. 1998. Efficacy and safety of rizatriptan vs standard care during long-term treatment for migraine. Rizatriptan Multicenter Study Groups. Headache, 38:764-7I. Copyright @ I 998, with permission from Blackwell Publishing Ltd.

Kolodny et al 2004). One study reported a significantly lower adverse event rate in patients receiving rizatriptan 5 and $10 \mathrm{mg}$ vs sumatriptan $100 \mathrm{mg}$ ( $27 \%$ and $33 \%$, respectively, vs $41 \%$; $<$ < 0.05) (Tfelt-Hansen et al 1998). Rizatriptan 5-mg tablets and wafers were also well tolerated in adolescents (Winner et al 2002; Visser et al 2004). Most studies reported no serious drug-related adverse events, and very few patients discontinued due to adverse events.

In a large, open, noncomparative study involving 33147 patients receiving treatment with rizatriptan $10 \mathrm{mg}$ in a clinical setting for up to 3 migraine attacks, repeated administration of rizatriptan was well tolerated, with very few adverse events reported (Göbel et al 2001). In this study, 0.9\% of patients experienced 1 or more adverse events, the most frequent of which were dizziness $(0.2 \%)$ and weakness-fatigue $(0.2 \%)$. A total of 157 patients discontinued rizatriptan owing to an unwanted drug effect, representing $6.3 \%$ of all patients who discontinued rizatriptan for any reason and $0.5 \%$ of patients enrolled on the study. Fewer than $4.5 \%$ of patients taking rizatriptan 5 or $10 \mathrm{mg}$ withdrew because of adverse events in long-term studies of rizatriptan treatment for multiple migraine attacks (Block et al 1998; Cady et al 2001).

In the randomized, double-blind, comparative trials, rizatriptan $10 \mathrm{mg}$ was associated with a higher degree of patient satisfaction with medication compared with sumatriptan $50 \mathrm{mg}$ (mean satisfaction on a scale from 1 "completely satisfied; couldn't be better" to 7 "completely dissatisfied; couldn't be worse": 3.28 vs 3.56 at 2 hours and 3.06 vs 3.39 at 4 hours; $\mathrm{p}<0.05$ both comparisons) (Goldstein et al 1998), zolmitriptan $2.5 \mathrm{mg}$ (mean 3.38 vs 3.67 at 2 hours; $p=0.038$ ) (Pascual et al 2000), naratriptan $2.5 \mathrm{mg}$ (mean 3.55 vs 4.21 at 2 hours; $\mathrm{p}<0.001$ ) (Bomhof et al 1999), and ergotamine $2 \mathrm{mg}$-caffeine $200 \mathrm{mg}$ (43.8\% vs $21.6 \%$ of patients completely satisfied or very satisfied at 2 hours; $\mathrm{p} \leq 0.001$ ) (Christie et al 2003).

In a randomized, open-label, crossover trial designed to compare preference for rizatriptan $10-\mathrm{mg}$ wafers vs sumatriptan 50-mg tablets, significantly more patients preferred rizatriptan than preferred sumatriptan $(64.3 \%$ vs $35.7 \%$; $\leq \leq 001$ ) (Pascual et al 2001). The most common reasons for rizatriptan treatment preference were faster relief of headache pain (46.9\% of patients), ease of use $(8.2 \%)$, and fewer side-effects $(6.1 \%)$. Similar results were seen in a second trial of similar design, with $57 \%$ of patients expressing a preference for rizatriptan 10-mg wafers compared with $43 \%$ of patients who preferred sumatriptan 50 -mg tablets $(\mathrm{p}=0.009)$ (Loder et al 2001). Among those patients with a stated preference, the most important reasons were faster pain relief ( $51 \%$ of patients), the ability to take the medication regardless of patient location $(8 \%$; only reported for rizatriptan wafer), and the ability to return to normal activities quicker (7\%). It is possible that treatment choice could have been influenced by the ease of use of the 
rizatriptan wafer formulation in these 2 studies. However, a relatively small percentage of patients reported this as the reason for treatment preference, and results of a separate retrospective nonblinded study in 367 patients showed that a similar number of patients preferred the $10-\mathrm{mg}$ wafer $(\mathrm{n}=188)$ and $10-\mathrm{mg}$ tablet $(\mathrm{n}=179)$ rizatriptan formulations (Adelman et al 2000), suggesting that formulation was probably not the key factor.

A greater proportion of patients preferred rizatriptan 10-mg tablets than preferred ergotamine 1-mg-caffeine 100-mg tablets in a randomized, double-blind, crossover trial $(69.9 \%$ vs $30.1 \%$ of 319 patients expressing a preference, respectively; $\mathrm{p} \leq 0.001)$, with faster relief of headache cited by the majority of these patients $(67.3 \%$ vs $54.2 \%$, respectively) as the most important reason for preference (Christie et al 2003).

Similarly, among patients who reported a treatment preference in a prospective, open-label, 2-attack study, more patients preferred rizatriptan 10-mg wafers than preferred their usual nontriptan therapy (nonsteroidal antiinflammatory drugs, analgesics, or ergot derivatives, used alone or in combination) $(78.8 \%$ vs $21.2 \%$, respectively; $\mathrm{p}<0.001)$. Overall, the most common reasons cited for preference of either treatment were faster relief of headache pain and faster return to normal function (Pascual et al 2005).

The quality of life benefits afforded by rizatriptan, as mentioned above (Santanello et al 1997; Goldstein et al 1998; Bomhof et al 1999; Pascual et al 2000), are consistent with the favorable efficacy and tolerability profile of the agent.

\section{Patient support and disease management programs}

The goals of migraine management are to treat attacks rapidly and consistently without recurrence, restore the patient's ability to function, minimize the use of rescue medications, optimize self-care and subsequent resource use, be cost effective, and have minimal or no adverse events (Silberstein and for the US Headache Consortium 2000).

British Association for the Study of Headache 2004 guidelines recommend a stepwise treatment approach as a means of achieving individualized therapy, starting patients on the safest and cheapest agents with known efficacy (BASH 2004). Treatment steps in ascending order are (i) a simple oral analgesic (eg, aspirin) with or without an antiemetic, (ii) a parenteral analgesic (eg, diclofenac) with or without an antiemetic, and (iii) a migraine-specific agent (eg, triptan). Patients should start on the first step, with treatment failure on 3 occasions being the suggested criterion for progression from one step to the next. The guidelines note that different treatment steps may be used in individual patients who experience attacks of different types or severities. The American Academy of Family Physicians and American College of Physicians-American Society of Internal Medicine (AAFP/ACP-ASIM) also recommend a stepwise treatment approach (Snow et al 2002).

In contrast, United States Headache Consortium 2000 guidelines advocate stratified treatment according to the severity of an individual migraine attack (Silberstein and for the US Headache Consortium 2000). Migraine-specific agents (eg, triptans) are recommended for the initial acute treatment of moderate-to-severe migraine where there are no contraindications for their use. Triptans are also considered appropriate for patients with mild-to-moderate headaches that respond poorly to nonsteroidal anti-inflammatory drugs or combinations such as aspirin plus caffeine (Silberstein and for the US Headache Consortium 2000). The relative benefits of stepwise and stratified treatment, and the place of triptans in initial migraine therapy, remain a matter for debate. However, there is evidence that stratified treatment provides more effective headache relief for patients with moderate-to-severe migraine-related disability than stepwise strategies used within or between migraine attacks (Lipton et al 2000).

While triptans are unlikely to cause substantial coronary vasoconstriction in patients with relatively healthy coronary arteries, their effects may be less predictable in patients with coronary artery disease; therefore, triptans are contraindicated in patients with ischemic heart disease, uncontrolled hypertension, a history of coronary vasospasm, and patients at high risk of asymptomatic coronary artery disease (Martin and Goldstein 2005). Concerns about the cardiovascular safety of the triptans led to an evaluation of triptanassociated cardiovascular risk by the Triptan Cardiovascular Safety Expert Panel of the American Headache Society, and a consensus statement arising from this evaluation concluded that triptans can be prescribed with confidence in patients with low risk of coronary artery disease (Dodick et al 2004).

Patients report greater satisfaction with migrainespecific triptan therapy than with analgesics, nonsteroidal anti-inflammatory drugs, or ergot derivatives (Ceballos Hernansanz et al 2003). British Association for the Study of Headache guidelines state that among the triptans, rizatriptan 10-mg tablet or wafer formulations are an appropriate 
choice for patients who require stronger oral treatment than sumatriptan (although, due to the pharmacological interaction described above [see pharmacokinetics section], patients receiving prophylactic propranolol should take rizatriptan $5 \mathrm{mg}$ ) (BASH 2004). United States Headache Consortium guidelines (Silberstein and for the US Headache Consortium 2000) make no recommendations as to which triptan should be selected. However, consideration should be given to those features considered by patients and physicians as being important in a migraine treatment. Research has shown that although a variety of attributes are desirable, rapid onset of complete pain relief is considered particularly important both by clinicians and patients (Lipton et al 2002). In a survey of US primary care physicians, rapid achievement of pain-free and sustained pain-free status were considered the most important efficacy attributes of triptan treatment (Cutrer et al 2004).

The TRIPSTAR project was developed to help physicians select oral triptans to best match patient needs by combining data on patient- and physician-reported treatment preferences with results from the aforementioned metaanalysis of triptan clinical trial data (see efficacy section) (Lipton et al 2005). When the data from the meta-analysis were evaluated using a Technique for Order Preference by Similarity to the Ideal Solution (TOPSIS) multi-attribute decision model, which considers attributes of the triptans weighted according to patient- and physician-reported treatment preferences, rizatriptan, along with almotriptan and eletriptan, was one of the closest available treatments to the hypothetical "ideal" triptan (defined as the best achievable with current technology) (Lipton et al 2005). It is interesting to note that the superiority of rizatriptan, almotriptan, and eletriptan relative to sumatriptan, naratriptan, and zolmitriptan in the above analysis was supported by a separate analysis using a TOPSIS model that considered all possible treatment attribute weightings, rather than importance weights determined in a particular study (Ferrari et al 2005).

The potential economic benefits of rizatriptan therapy may also be taken into account when selecting from among the oral triptans. An open-label workplace study in 259 Spanish migraineurs showed that treatment with rizatriptan for 3 months led to significant reductions in the use of medical services, absenteeism, and loss of productivity, as well as improved quality of life compared with the 3 months before starting rizatriptan (Láinez et al 2005). Similarly, a recent analysis determined that substantial productivity costs of migraine to the US employer could be significantly reduced if rizatriptan were used instead of patients' existing therapies (Gerth et al 2004). Moreover, a US cost-effectiveness analysis performed from a societal perspective showed that rizatriptan was more cost-effective in the treatment of acute migraine than sumatriptan or ergotamine-caffeine, reflecting both reduced costs and greater effectiveness (as measured by quality-adjusted life-years gained) (Zhang and Hay 2005). In a meta-analysis of randomized, placebo-controlled trials of single-dose oral triptans, rizatriptan $10 \mathrm{mg}$ had the most advantageous cost-effectiveness ratio vs other triptans (almotriptan, eletriptan, frovatriptan, naratriptan, zolmitriptan, and sumatriptan) when results were compared using drug cost data from the US, the UK, Canada, Germany, Italy, and The Netherlands, although the levels of statistical significance vs comparators varied between countries (Belsey 2004).

\section{Conclusion}

According to current guidelines advocating stepwise or stratified treatment approaches, triptans are recommended for the acute treatment of migraine unlikely to respond to less effective therapy. A number of triptans are available; however, rizatriptan has several advantages over other members of its class (Table 3 ). Rizatriptan reaches maximum plasma concentrations quickly, with a shorter $\mathrm{t}_{\max }$ than other available triptans, and produces rapid onset of pain relief. This may prove advantageous in the early treatment of migraine, allowing rapid relief of mild pain before an attack becomes moderate to severe. Comparative clinical trials have shown that for the acute treatment of migraine rizatriptan is at least as effective as, or superior to, other oral migraine-specific agents. Rizatriptan has demonstrated efficacy over the long term (up to 12 months) in the treatment of multiple migraine attacks, and appears to have more consistent efficacy across multiple attacks than other triptans. Rizatriptan is generally well tolerated, with an overall incidence of adverse events and quality of life benefits similar to other triptans. It is associated with a higher degree of patient satisfaction than other migraine-specific agents, with rapid pain relief, ease of use (wafer formulation), and tolerability being important reasons for patient preference. Multi-attribute decision models incorporating efficacy data and weighted clinical attributes identify rizatriptan as one of three triptans closest to a hypothetical ideal. In conclusion, rizatriptan is a wellestablished, effective, and well-tolerated agent for the acute treatment of migraine. 
Table 3 Clinical summary of rizatriptan in the treatment of migraine

\begin{tabular}{|c|c|c|c|c|}
\hline Key pharmacologic features & Patient preference & Tolerability & Efficacy & Potential economic benefits \\
\hline $\begin{array}{l}\text { - Rapidly and completely } \\
\text { ( } 90 \%) \text { absorbed from } \\
\text { gastrointestinal tract } \\
\text { - Shorter time to maximum } \\
\text { plasma concentration } \\
\text { (I-I.5 hours) than other } \\
\text { triptans } \\
\text { - Pharmacokinetics } \\
\text { unaffected by occurrence } \\
\text { of migraine attack } \\
\text { - Plasma concentration } \\
\text { increased in patients } \\
\text { receiving propranolol }\end{array}$ & $\begin{array}{l}\text { - Higher degree of } \\
\text { patient satisfaction } \\
\text { than other migraine- } \\
\text { specific agents } \\
\text { - Important reasons } \\
\text { for patient } \\
\text { preference include } \\
\text { rapid pain relief, } \\
\text { ease of use (wafer), } \\
\text { and tolerability }\end{array}$ & $\begin{array}{l}\text { - Generally well } \\
\text { tolerated } \\
\text { - Overall incidence } \\
\text { of adverse events } \\
\text { similar to other } \\
\text { triptans } \\
\text { - Commonest } \\
\text { adverse events } \\
\text { (dizziness, } \\
\text { somnolence, } \\
\text { asthenia-fatigue, } \\
\text { dry mouth, nausea, } \\
\text { chest pain) are } \\
\text { predominantly } \\
\text { transient and mild } \\
\text { to moderate in } \\
\text { intensity } \\
\text { - Migraine-specific } \\
\text { quality of life ben- } \\
\text { efits comparable } \\
\text { to other triptans }\end{array}$ & $\begin{array}{l}\text { - Efficacious in } \\
\text { placebo-controlled } \\
\text { trials } \\
\text { - Comparable or supe- } \\
\text { rior efficacy to sumat- } \\
\text { riptan } 50 \text { or I00 mg } \\
\text { zolmitriptan } 2.5 \text { or } \\
5.0 \text { mg naratriptan } \\
2.5 \text { mg almotriptan } \\
\text { I2.5 mg ergotamine/ } \\
\text { caffeine } 2 \text { mg/200 mg } \\
\text { - Provides more rapid } \\
\text { pain relief than other } \\
\text { migraine-specific } \\
\text { agents } \\
\text { - Consistent efficacy } \\
\text { over } 6 \text {-I } 2 \text { months } \\
\text { - More consistent } \\
\text { intra-patient efficacy } \\
\text { than other triptans } \\
\text { - One of three triptans } \\
\text { closest to a } \\
\text { hypothetical “ideal” } \\
\text { offective in menstrually } \\
\text { efficacy in adolescents }\end{array}$ & $\begin{array}{l}\text { - Reduction in use of medical } \\
\text { services vs prior therapies } \\
\text { - Reduced productivity costs } \\
\text { compared with usual therapy } \\
\text { - Advantageous cost-effective } \\
\text { ratio vs other triptans, } \\
\text { including sumatriptan }\end{array}$ \\
\hline
\end{tabular}

\section{Disclosures}

Professor Miguel Láinez has received grant/research support from, has been a consultant/scientific advisor for, or has received honoraria for oral presentations from Allergan, Almirall Prodesfarma, Böhringer Ingelheim, Bristol-Myers Squibb, Elan Pharmaceuticals, GlaxoSmithKline, Janssen Cilag, Johnson \& Johnson, Menarini, MSD, Novartis, Pierre Fabre, and Sanofi-Synthelabo.

\section{References}

Adelman JU, Lipton RB, Ferrari MD, et al. 2001. Comparison of rizatriptan and other triptans on stringent measures of efficacy. Neurology, 57:1377-83.

Adelman JU, Mannix LK, Von Seggern RL. 2000. Rizatriptan tablet vs wafer: patient preference. Headache, 40:371-2.

Ahrens SP, Farmer MV, Williams DL, et al. 1999. Efficacy and safety of rizatriptan wafer for the acute treatment of migraine. Rizatriptan Wafer Protocol 049 Study Group. Cephalalgia, 19:525-30.

Belsey JD. 2004. Cost effectiveness of oral triptan therapy: a trans-national comparison based on a meta-analysis of randomised controlled trials. Curr Med Res Opin, 20:659-69.
Berg J, Stovner LJ. 2005. Cost of migraine and other headaches in Europe. Eur J Neurol, 12(Suppl 1):59-62.

Bianchi G, Passoni A, Griffini PL. 1989. Effects of a new calcium antagonist, Rec 15/2375, on cardiac contractility of conscious rabbits. Pharmacol Res, 21:193-200.

Block GA, Goldstein J, Polis A, et al. 1998. Efficacy and safety of rizatriptan vs standard care during long-term treatment for migraine. Rizatriptan Multicenter Study Groups. Headache, 38:764-71.

Bomhof M, Paz J, Legg N, et al. 1999. Comparison of rizatriptan $10 \mathrm{mg}$ vs naratriptan $2.5 \mathrm{mg}$ in migraine. Eur Neurol, 42:173-9.

[BASH] British Association for the Study of Headache. 2004. Guidelines for all doctors in the diagnosis and management of migraine and tensiontype headache, 2nd ed [online]. Accessed 19 September 2005. URL: http://www.bash.org.uk/.

Bussone G, D'Amico D, McCarroll KA, et al. 2002. Restoring migraine sufferers' ability to function normally: a comparison of rizatriptan and other triptans in randomized trials. Eur Neurol, 48:172-7.

Cady R, Crawford G, Ahrens S, et al. 2001. Long-term efficacy and tolerability of rizatriptan wafers in migraine [online]. Med Gen Med, 3(4). URL: http://www.medscape.com/viewarticle/408137.

Ceballos Hernansanz MA, Sanchez RR, Cano Org, et al. 2003. Migraine treatment patterns and patient satisfaction with prior therapy: a substudy of a multicenter trial of rizatriptan effectiveness. Clin Ther, 25:2053-69.

Cheng H, Polvino WJ, Sciberras D, et al. 1996. Pharmacokinetics and food interaction of MK-462 in healthy males. Biopharm Drug Dispos, $17: 17-24$. 
Christie S, Gobel H, Mateos V, et al. 2003. Crossover comparison of efficacy and preference for rizatriptan $10 \mathrm{mg}$ vs ergotamine/caffeine in migraine. Eur Neurol, 49:20-9.

Cumberbatch MJ, Hill RG, Hargreaves RJ. 1997. Rizatriptan has central antinociceptive effects against durally evoked responses. Eur $J$ Pharmacol, 328:37-40.

Cutler NR, Jhee SS, Majumdar AK, et al. 1999. Pharmacokinetics of rizatriptan tablets during and between migraine attacks. Headache, 39:264-9.

Cutrer FM, Goadsby PJ, Ferrari MD, et al. 2004. Priorities for triptan treatment attributes and the implications for selecting an oral triptan for acute migraine: a study of US primary care physicians (the TRIPSTAR Project). Clin Ther, 26:1533-45.

Dahlof CG, Lipton RB, McCarroll KA, et al. 2000. Within-patient consistency of response of rizatriptan for treating migraine. Neurology, 55:1511-6.

Dodick D, Lipton RB, Martin V, et al. 2004. Consensus statement: cardiovascular safety profile of triptans (5-HT agonists) in the acute treatment of migraine. Headache, 44:414-25.

Ferrari MD, Goadsby PJ, Lipton RB, et al. 2005. The use of multiattribute decision models in evaluating triptan treatment options in migraine. J Neurol, 252:1026-32.

Ferrari MD, Goadsby PJ, Roon KI, et al. 2002. Triptans (serotonin, 5-HT1B/1D agonists) in migraine: detailed results and methods of a meta-analysis of 53 trials. Cephalalgia, 22:633-58.

Ferrari MD, Loder E, McCarroll KA, et al. 2001. Meta-analysis of rizatriptan efficacy in randomized controlled clinical trials. Cephalalgia, 21:129-36.

Gerth WC, Sarma S, Hu XH, et al. 2004. Productivity cost benefit to employers of treating migraine with rizatriptan: a specific worksite analysis and model. J Occup Environ Med, 46:48-54.

Gijsman H, Kramer MS, Sargent J, et al. 1997. Double-blind, placebocontrolled, dose-finding study of rizatriptan (MK-462) in the acute treatment of migraine. Cephalalgia, 17:647-51.

Goadsby PJ, Hargreaves RJ. 2000. Mechanisms of action of serotonin 5-HT1B/D agonists: insights into migraine pathophysiology using rizatriptan. Neurology, 55:S8-14.

Goadsby PJ, Lipton RB, Ferrari MD. 2002. Migraine - current understanding and treatment. $N$ Engl J Med, 346:257-70.

Göbel H, Heinze A, Heinze-Kuhn K, et al. 2001. Efficacy and tolerability of rizatriptan $10 \mathrm{mg}$ in migraine: experience with 70527 patient episodes. Headache, 41:264-70.

Goldberg MR, Lee Y, Vyas KP, et al. 2000. Rizatriptan, a novel 5-HT1B/1D agonist for migraine: single- and multiple-dose tolerability and pharmacokinetics in healthy subjects. $J$ Clin Pharmacol, 40:74-83.

Goldberg MR, Sciberras D, De Smet M, et al. 2001. Influence of betaadrenoceptor antagonists on the pharmacokinetics of rizatriptan, a 5-HT1B/1D agonist: differential effects of propranolol, nadolol and metoprolol. Br J Clin Pharmacol, 52:69-76.

Goldstein J, Ryan R, Jiang K, et al. 1998. Crossover comparison of rizatriptan $5 \mathrm{mg}$ and $10 \mathrm{mg}$ vs sumatriptan $25 \mathrm{mg}$ and $50 \mathrm{mg}$ in migraine. Rizatriptan Protocol 046 Study Group. Headache, 38:737-47.

Gori S, Morelli N, Bellini G, et al. 2005. Rizatriptan does not change cerebral blood flow velocity during migraine attacks. Brain Res Bull, 65:297-300.

[HCS] Headache Classification Subcommittee of the International Headache Society. 2004. The International Classification of Headache Disorders, 2nd ed. Cephalalgia, 24(Suppl 1):9-160.

Hu XH, Markson LE, Lipton RB, et al. 1999. Burden of migraine in the United States: disability and economic costs. Arch Intern Med, 159:813-8.

Jamieson D, Cutrer FM, Goldstein J, et al. 2003. Real-world experiences in migraine therapy with rizatriptan. Headache, 43:223-30.

Kolodny A, Polis A, Battisti WP, et al. 2004. Comparison of rizatriptan $5 \mathrm{mg}$ and $10 \mathrm{mg}$ tablets and sumatriptan $25 \mathrm{mg}$ and $50 \mathrm{mg}$ tablets. Cephalalgia, 24:540-6.
Kramer MS, Matzura-Wolfe D, Polis A, et al. 1998. A placebo-controlled crossover study of rizatriptan in the treatment of multiple migraine attacks. Rizatriptan Multiple Attack Study Group. Neurology, 51:773-81.

Láinez MJ, Lopez A, Pascual AM. 2005. Effects on productivity and quality of life of rizatriptan for acute migraine: a workplace study. Headache, 45:883-90.

Lee Y, Conroy JA, Stepanavage ME, et al. 1999. Pharmacokinetics and tolerability of oral rizatriptan in healthy male and female volunteers. Br J Clin Pharmacol, 47:373-8.

Leira R, Dualde E, del Barrio H, et al. 2003. Almotriptan vs rizatriptan in patients with migraine in Spain. Headache, 43:734-41.

Lipton RB, Bigal ME. 2005. Migraine: epidemiology, impact, and risk factors for progression. Headache, 45(Suppl 1):S3-13.

Lipton RB, Bigal ME, Kolodner K, et al. 2003. The family impact of migraine: population-based studies in the USA and UK. Cephalalgia, 23:429-40.

Lipton RB, Cutrer FM, Goadsby PJ, et al. 2005. How treatment priorities influence triptan preferences in clinical practice: perspectives of migraine sufferers, neurologists, and primary care physicians. Curr Med Res Opin, 21:413-24.

Lipton RB, Hamelsky SW, Dayno JM. 2002. What do patients with migraine want from acute migraine treatment? Headache, 42(Suppl 1):3-9.

Lipton RB, Pascual J, Goadsby PJ, et al. 2001a. Effect of rizatriptan and other triptans on the nausea symptom of migraine: a post hoc analysis. Headache, 41:754-63.

Lipton RB, Stewart WF. 1999. Acute migraine therapy: do doctors understand what patients with migraine want from therapy? Headache, 39(Suppl 2):S20-6.

Lipton RB, Stewart WF, Diamond S, et al. 2001b. Prevalence and burden of migraine in the United States: data from the American Migraine Study II. Headache, 41:646-57.

Lipton RB, Stewart WF, Stone AM, et al. 2000. Stratified care vs step care strategies for migraine: the Disability in Strategies of Care (DISC) Study: A randomized trial. JAMA, 284:2599-605.

Loder E, Brandes JL, Silberstein S, et al. 2001. Preference comparison of rizatriptan ODT 10-mg and sumatriptan 50-mg tablet in migraine. Headache, 41:745-53.

Longmore J, Hargreaves RJ, Boulanger CM, et al. 1997. Comparison of the vasoconstrictor properties of the 5-HT1D-receptor agonists rizatriptan (MK-462) and sumatriptan in human isolated coronary artery: outcome of two independent studies using different experimental protocols. Funct Neurol, 12:3-9.

Longmore J, Razzaque Z, Shaw D, et al. 1998. Comparison of the vasoconstrictor effects of rizatriptan and sumatriptan in human isolated cranial arteries: immunohistological demonstration of the involvement of 5-HT1B-receptors. Br J Clin Pharmacol, 46:577-82.

MaassenVanDenBrink A, Reekers M, Bax WA, et al. 1998. Coronary side-effect potential of current and prospective antimigraine drugs. Circulation, 98:25-30.

Martin VT, Goldstein JA. 2005. Evaluating the safety and tolerability profile of acute treatments for migraine. Am J Med, 118(Suppl 1): S36-44.

Mathew NT, Kailasam J, Gentry P, et al. 2000. Treatment of nonresponders to oral sumatriptan with zolmitriptan and rizatriptan: a comparative open trial. Headache, 40:464-5.

Mathew NT, Kailasam J, Meadors L. 2004. Early treatment of migraine with rizatriptan: a placebo-controlled study. Headache, 44:669-73.

Merck \& Co Inc. 2003. Maxalt ${ }^{\circledR}$ (rizatriptan benzoate tablets) and Maxalt-MLT $^{\circledR}$ (rizatriptan benzoate orally disintegrating tablets): United States prescribing information. New Jersey, USA: Merck \& Co, Inc.

Musson DG, Birk KL, Panebianco DL, et al. 2001. Pharmacokinetics of rizatriptan in healthy elderly subjects. Int J Clin Pharmacol Ther, $39: 447-52$ 
Okazawa H, Tsuchida T, Pagani M, et al. 2006. Effects of 5-HT(1B/1D) receptor agonist rizatriptan on cerebral blood flow and blood volume in normal circulation. J Cereb Blood Flow Metab, 26:92-8.

Pascual J, Bussone G, Hernandez JF, et al. 2001. Comparison of preference for rizatriptan 10-mg wafer vs sumatriptan 50-mg tablet in migraine. Eur Neurol, 45:275-83.

Pascual J, Garcia-Monco C, Roig C, et al. 2005. Rizatriptan 10-mg wafer vs usual nontriptan therapy for migraine: analysis of return to function and patient preference. Headache, 45:1140-50.

Pascual J, Vega P, Diener HC, et al. 2000. Comparison of rizatriptan $10 \mathrm{mg}$ vs zolmitriptan $2.5 \mathrm{mg}$ in the acute treatment of migraine. RizatriptanZolmitriptan Study Group. Cephalalgia, 20:455-61.

Santanello NC, Hartmaier SL, Epstein RS, et al. 1995. Validation of a new quality of life questionnaire for acute migraine headache. Headache, 35:330-7.

Santanello NC, Polis AB, Hartmaier SL, et al. 1997. Improvement in migraine-specific quality of life in a clinical trial of rizatriptan. Cephalalgia, 17:867-72.

Sciberras DG, Polvino WJ, Gertz BJ, et al. 1997. Initial human experience with MK-462 (rizatriptan): a novel 5-HT1D agonist. Br J Clin Pharmacol, 43:49-54.

Silberstein SD, for the US Headache Consortium. 2000. Practice parameter: evidence-based guidelines for migraine headache (an evidence-based review): report of the Quality Standards Subcommittee of the American Academy of Neurology. Neurology, 55:754-62.

Silberstein SD, Massiou H, Le Jeunne C, et al. 2000. Rizatriptan in the treatment of menstrual migraine. Obstet Gynecol, 96:237-42.

Silberstein SD, Massiou H, McCarroll KA, et al. 2002. Further evaluation of rizatriptan in menstrual migraine: retrospective analysis of long-term data. Headache, 42:917-23.

Snow V, Weiss K, Wall EM, et al. 2002. Pharmacologic management of acute attacks of migraine and prevention of migraine headache. Ann Intern Med, 137:840-9.

Sperling B, Tfelt-Hansen P. 1995. Lack of effect of MK-462 on cerebral blood flow in man. Cephalalgia, 15(Suppl 14):206. Abstract p5.

Teall J, Tuchman M, Cutler N, et al. 1998. Rizatriptan (MAXALT) for the acute treatment of migraine and migraine recurrence. A placebo-controlled, outpatient study. Rizatriptan 022 Study Group. Headache, 38:281-7.
Tfelt-Hansen P, Block G, Dahlof C, et al. 2000a. Guidelines for controlled trials of drugs in migraine: second edition. Cephalalgia, 20:765-86.

Tfelt-Hansen P, Saxena PR, Dahlof C, et al. 2000b. Ergotamine in the acute treatment of migraine: a review and European consensus. Brain, 123:9-18.

Tfelt-Hansen P, Seidelin K, Stepanavage M, et al. 2002. The effect of rizatriptan, ergotamine, and their combination on human peripheral arteries: a double-blind, placebo-controlled, crossover study in normal subjects. Br J Clin Pharmacol, 54:38-44.

Tfelt-Hansen P, Teall J, Rodriguez F, et al. 1998. Oral rizatriptan vs oral sumatriptan: a direct comparative study in the acute treatment of migraine. Rizatriptan 030 Study Group. Headache, 38:748-55.

Visser WH, Terwindt GM, Reines SA, et al. 1996. Rizatriptan vs sumatriptan in the acute treatment of migraine. A placebo-controlled, dose-ranging study. Dutch/US Rizatriptan Study Group. Arch Neurol, $53: 1132-7$.

Visser WH, Winner P, Strohmaier K, et al. 2004. Rizatriptan $5 \mathrm{mg}$ for the acute treatment of migraine in adolescents: results from a doubleblind, single-attack study and two open-label, multiple-attack studies. Headache, 44:891-9.

Vollono C, Capuano A, Mei D, et al. 2005. Multiple attack study on the available triptans in Italy vs placebo. Eur J Neurol, 12:557-63.

Vyas KP, Halpin RA, Geer LA, et al. 2000. Disposition and pharmacokinetics of the antimigraine drug, rizatriptan, in humans. Drug Metab Dispos, 28:89-95.

Williamson DJ, Hill RG, Shepheard SL, et al. 2001. The anti-migraine 5-HT1B/1D agonist rizatriptan inhibits neurogenic dural vasodilation in anaesthetized guinea-pigs. Br J Pharmacol, 133:1029-34.

Williamson DJ, Shepheard SL, Hill RG, et al. 1997. The novel antimigraine agent rizatriptan inhibits neurogenic dural vasodilation and extravasation. Eur J Pharmacol, 328:61-4.

Winner P, Lewis D, Visser WH, et al. 2002. Rizatriptan $5 \mathrm{mg}$ for the acute treatment of migraine in adolescents: a randomized, double-blind, placebo-controlled study. Headache, 42:49-55.

Zhang L, Hay JW. 2005. Cost-effectiveness analysis of rizatriptan and sumatriptan vs $\mathrm{Cafergot}^{\circledR}$ in the acute treatment of migraine. CNS Drugs, 19:635-42. 
